\title{
Equity of access: can consortia and clinical knowledge programmes truly address the imbalance? An Australian view
}

\author{
Marijana Bacic
}

\begin{abstract}
A number of clinical knowledge programmes have been implemented by several states and one territory in Australia with the shared aim of providing an electronic library of health information to professionals within the clinical setting. These programmes supplement library initiatives that have resulted in the formation of consortia for the purchase of certain electronic resources and other cooperative ventures that aim to redistribute the costs associated with the provision of clinical information. A review of the literature was conducted, and the World Wide Web was searched. The information obtained was substantiated with data gathered from informal conversations and semistructured interviews. An overview of one consortium and five clinical knowledge programmes is provided in terms of its development and administration. These initiatives have unequivocally improved the availability of clinical information resources for eligible institutions. However, not all health organisations have been able to benefit from these ventures. While membership in some consortia is open to all organisations involved in the health industry, eligibility for access to these six initiatives is more strictly defined. Access to licenced knowledge resources provided by these initiatives, in most cases, is restricted to public health institutions funded by the relevant state or territory government. Organisations ineligible to access resources provided by these initiatives must therefore look to consortia as a means of providing access to electronic resources, if their budgets allow. While not providing the complete solution, consortia and clinical knowledge programmes provide a good foundation for addressing the inequity of access to health information.
\end{abstract}

\section{Introduction}

Information provision and the selection of information resources has long been the domain of librarians. This role has extended to the provision and selection of electronic resources since the introduction of electronic media. In Australia, significant developments have taken place in the field of clinical information provision in recent years. A number of initiatives have been established, namely, five clinical knowledge programmes and one consortium. Each initiative was established in a state or territory delivering information via an electronic library bearing the name of the respective programme. These electronic libraries are available only to clinicians of eligible institutions, with existing traditional libraries playing an important role in training and marketing, and in the integration of these resources into their intranets. The programmes and consortium aim to provide access to vital information to clinicians at point of care, $24 \mathrm{~h}$ per day, 7 days per week. Not only do these initiatives provide information resources that are necessary for the practicing clinician, but they also provide a means of facilitating evidence-based clinical practice. This emphasis on evidence-based practice also eventuated in another significant

M. Bacic. Southern Health Library Network, Melbourne, Victoria, Australia (e-mail:

marijana.bacic@med.monash.edu.au). development for Australian clinicians - a national site licence for the provision of the Cochrane database to all Australians, financed by the Australian Commonwealth government.

The scope of this paper is limited to the examination of the question of whether these five programmes and one consortium can redress the inequity of information access. The basis for this is simple: these initiatives stand out as major developments in their respective states and territory in the attempt to provide access to a large number of electronically accessible clinical information resources. The significance to hospital libraries unable to provide resources on such a scale is clear. Organisations with small or poorly funded libraries that are ineligible to take part in any of these initiatives must look toward library consortia as a means of being able to provide access to electronically available clinical information. In such cases, the resources that are available through consortia are usually vendor specific (e.g. ProQuest, Blackwell Publishing) and do not provide access to the number of resources that have been provided by the six initiatives that will be the focus of this paper.

\section{Background}

Funding of Australian public health services

The Commonwealth of Australia is a federation of six 
states and two territories and is governed by the Commonwealth government and the state and territory governments. Each state and territory has its own local government authorities. Thus, in terms of funding, each state and territory has its own health department that coordinates and distributes funds to the public health facilities provided by the Commonwealth government to the state or territory, as well as funds raised from state or territory government revenue. Additional funding may come in the form of Commonwealth-funded national health directives, from nongovernment sources such as the fundraising activities of individual health institutions (usually the larger hospitals), and from "out-of-pocket expenditure [for services charges in excess of, or not covered by, the Commonwealth-funded Medicare rebate] paid by individuals and benefits paid by private health insurance" [1]. While the Commonwealth government may provide some direction in policy, the responsibility for the administration and funding of public hospitals, for instance, is that of the individual states and territories [2]. "State and territory governments... provide most of the funding for community health services and public health activities" [3].

Public hospitals affiliated with universities, traditionally those with medical schools, receive additional funding from a Commonwealth government grant, which provides universities with funds that are distributed by universities to each of their teaching hospitals. "It is up to the faculty of medicine staff in each university as to the proportion of their grant [that] actually reaches teaching hospital libraries" [4].

Australia's health services operate from a number of private and public hospitals and health facilities. Based on data from the Australian Hospitals Directory, public hospitals make up 58\% of all hospitals in Australia [5].

\section{Method}

The disparity in the amount of information available in the literature and on the Web regarding each of the clinical knowledge programmes indicated a need for further research, particularly if a balanced account and overview of each programme was to be attempted. While some of the programmes have been well documented, there are a number that are not, and without further investigation, attempts to provide overviews of all the respective programmes would have been thwarted. In fact, it was impossible to locate one article that provides a brief history of all of these programmes. In addition to the Web, the following databases were searched: MEDLINE, CINAHL, Meditext, AustHealth, LISA, and ALISA.

Semistructured interviews with key individuals was considered the most appropriate means of gathering the required information. This method provides the interviewer with the flexibility to follow up on information provided by the interviewee during the course of the interview [6]. It also provides the interviewer with the opportunity to confirm or repeat anything that may be unclear from the respondent's answers to minimize error. Furthermore, it was felt that mailed questionnaires would not have been appropriate as it does not permit the flexibility provided by semistructured interviews, and the response rates "rarely exceed 50\%, and can be as low as 15\%" [7]. Emphasis was on obtaining information that otherwise may not have been made available. Interviewees were not randomly selected. The interviews were conducted with either librarians involved with the programme in some way since its implementation or current or past managers of the programme. In some instances interviews were conducted with both when it was considered necessary to obtain further information.

Although it is common practice to record interviews on tape and conduct interviews in person [8], the interviews upon which this paper is based were conducted by telephone and were not recorded on tape. Telephone interviews were deemed necessary in this case because of distance issues and time constraints, as the interviewees were located in the capital cities of four states and one territory.

Evaluations have been carried out on four of the programmes. However, the results will not be discussed in this paper. Different types of surveys were conducted, and in the case of the programme in Victoria, the only major evaluation conducted was briefly made available and then withdrawn from the programme's Web site. Further attempts to obtain it were met with a response from the department stating that the report was being revised. In the case of the Western Australian programme, results were provided, but the actual report had not been viewed. Consequently, an assessment regarding the appropriateness of the research design and the validity of the conclusions drawn from these evaluations could not be made. As this would not provide a uniform basis for an effective comparison across the programmes and since no evaluation of the programme in the Australian Capital Territory was conducted, the results of the evaluations have been excluded.

\section{Results}

\section{Clinical Information Access Project}

This programme was the first of its kind to be introduced in Australia. The Clinical Information Access Project $(\text { CIAP })^{1}$ is considered a "precursor" to the UK National electronic Library for Health (NeLH) [9]. CIAP was established in July 1997 [10] in the state of New South Wales (NSW), which has a population of over 6.5 million [11]. It was originally established to provide access to clinical information resources to clinicians in rural areas because they were viewed as being disadvantaged by distance and lacking in library facilities. But pressure from their metropolitan counterparts saw an extension of the original programme to include public hospitals and services in the city.

Although the programme was initially funded by the state government, a long-term funding solution was sought from the outset and established during its initial stages. The programme has since been funded by the public area health services, with the contribution of each area health service determined by a resource distribution formula based on the number and size of the hospitals, the number of teaching

\footnotetext{
${ }^{1}$ Unless otherwise indicated, information is based on data obtained during an interview in May 2004, with Gillian Wood, a librarian who has been involved with CIAP since its inception.
} 
hospitals, and the number of staff and beds (P. Romain, personal communication, 2004).

During the initial phase of the programme, hardware was distributed in the form of one personal computer for each hospital and access to MEDLINE, CINAHL, and OVID's electronic journals was provided.

At present, electronic resources are selected by a committee. The current committee has a number of librarians who participate in the decision making process of this group in the selection of resources. The programme's resources are available to all health professionals employed by the NSW public health system and general practitioners in rural areas.

CIAP's current and rather impressive list of resources includes MIMS (Australian pharmaceutical information), Australian Medicines Handbook, MD Consult, Micromedex, PsycINFO, CINAHL, MEDLINE, Clinical Evidence, ACP Journals Club, Harrison's Online, STAT!Ref, the Natural Medicines database, and others [12]. These resources can be searched using the Unified Search Environment (USE) software, which permits federated or simultaneous searching of these resources.

\section{South Australian Human Services Libraries Consortium}

The next electronic library that was established was SALUS. It was established in 1999 [13] by the South Australian Human Services Libraries Consortium in South Australia. South Australia has a population of over 1.5 million [14]. Of the initiatives, this is the only consortium for which an overview will be provided because the consortium attempts to provide a comprehensive number of clinical information resources on a large scale and therefore is quite significant in comparison to all other existing health consortia. In fact, this particular consortium model has been taken up by Victorian health librarians as the basis of their consortium. This initiative differs to CIAP and the other programmes mentioned later in this paper because its management and resource selection process is performed entirely by the health librarians themselves.

This consortium is made up of state government funded health libraries and includes large teaching hospitals and small community outreach organisations [15]. Resources are selected in a more flexible way than are the resources for programmes such as CIAP. Participating libraries are able to select which of the resources they wish to subscribe to without having to accept the full suite of resources made available via the SALUS Web site [16]. State government funding was provided initially but ceased at the end of the financial year in 2002. Funding of resources has since been provided from the budgets of participating libraries [17].

The consortium is managed by a Consortium Management Committee that has the authority to act on behalf of member libraries. However, the decisions made are subject to approval by member libraries.

Resources currently subscribed to by member libraries include MEDLINE, CINAHL, EMBASE, PsycINFO, Clinical Evidence, the Australian Medicines Handbook online, MIMS, Therapeutic Guidelines, Harrison's Online, APAIS, AustHealth, MDConsult, STAT!Ref, Proquest Health \& Medical Complete, and other electronic resources (L. Harris,
Chair, Consortium Management Group, personal communication, 2004).

\section{Clinicians Health Channel}

The second programme established in Australia was the Clinicians Health Channel (CHC). It was introduced in March 2000 [18], in the state of Victoria, which has a population of almost 5 million [19]. This pilot project is currently in its final phase, with 4 years of funding provided by a Commonwealth government grant administered by the state's Department of Human Services. The funding is scheduled to cease in August 2004. At this stage, it is unclear how the programme will continue to function after August 2004. But in recent weeks, events have taken place that would suggest that the programme will continue for at least another 3 years. Although there has been no confirmation from the Department, this assumption is based on the advertisement that appeared on June 28 in the Melbourne newspaper The Age, calling for invitations to tender [20]. No contact with key health librarians has been attempted by the Department [21], and no official statement has been made. Furthermore, it is not certain what form the continued model will take and if the programme, as suggested by the tender document, will in fact be centrally funded for an additional 3 years by the Department. This lack of communication has created a sense of uneasiness among health librarians in Victoria [22].

Victorian health librarians have nevertheless interpreted this as a victory, the size of which can only be determined when the final details of the new $\mathrm{CHC}$ are unveiled by the Department. The implied continuation of the programme emphasizes the success of the health librarians who were pivotal in the lobbying process that eventuated in many letters and e-mails from concerned Victorian clinicians being sent to the State Minister for Health and the support from the Australian Medical Association and chief executives of major hospitals. Furthermore, support for the continuation of CHC was taken up by the Victorian state branch of the Liberal Party (the current government opposition party), which pledged to support a continued $\mathrm{CHC}$ if elected to power [23].

The programme was modelled on CIAP. Initial consultation was made with key stakeholders including librarians. A committee was then established comprising individuals representing the Department responsible for the administration of the pilot, allied health professionals, the Centre for Clinical Effectiveness (Southern Health-Monash University), the libraries, nurses, and physicians. Although the committee was consulted regarding the selection of various electronic resources, in practice, decisions were made by the Department.

The current CHC programme provides access to clinical information resources to Victoria's public hospitals, community health centres, and general medical practitioners in rural areas. Resources currently offered by the programme include MIMS, Micromedex, Clinical Evidence, MEDLINE, CINAHL, PsycINFO, AustHealth, Meditext, and others [24]. Based on the tender document, it appears as though most of the resources that are currently available will continue as part of the new CHC. 


\section{Clinical Information Access Online}

The Clinical Information Access Online (CIAO) programme ${ }^{2}$ was the third programme established. It was established in Western Australia, Australia's largest state by area but with a population of only 2 million [25]. It was established in April 2000, by the state's health department with funding secured from state and Commonwealth government sources. It was modelled on the NSW programme CIAP.

The CIAO ceased to operate in July 2003, when funding ran out. No immediate agreement was reached between the area health services and the department regarding continued funding. Disagreement arose regarding the proposal that each area health service contribute a portion of their budgets to finance the continuation of the programme. Because of the numbers of e-mails received by the health department from clinicians who had become accustomed to using these resources, a decision was made by the department's executive management team, and CIAO was reborn. The programme was reinstated in November 2003, with funds from each of the area health services budgets contributing towards the costs. The contribution of each area health service in Western Australia to CIAO is determined by the percentage of the public health budget that is received by the health service.

No librarians were involved with the initial implementation of the programme, including the selection of initial resources; however, the second stage or the reinstated version of CIAO involved some input from a representative librarian who assisted the programme manager in the selection of resources. Recommendations, in terms of resources, can be made by the reference group, which includes a number of librarians and clinicians. Decisions, however, are made by the state health executive management team.

The CIAO provides access to those employed in the public health sector in Western Australia, visiting medical practitioners, general practitioners in rural areas, and the Royal Flying Doctor Service.

Current resources offered by CIAO include MEDLINE, CINAHL, Therapeutic Guidelines, MIMS, Micromedex, Harrison's, PsycINFO, electronic journals, and AustHealth [26]. The original project offered more resources than is currently available. However, additional resources will be added in the future with the ultimate goal being the provision of CIAO resources to all health professionals in Western Australia. It is envisaged that access to such resources will be open to all (public or private) health care facilities and the costs shared accordingly. Participants of such a programme would be able to choose which resources offered will be subscribed to, without having to take on the full suite of resources.

\section{Clinicians Knowledge Network}

The Clinicians Knowledge Network $(\mathrm{CKN})^{3}$ began operation in March 2001 [27], in the state of Queensland, the sec- ond largest state in Australia by area, with a population of almost 2 million [28]. A Commonwealth government grant funded the first 2 years of the programme, with a continued funding model now in place based on the number of full-time equivalent (FTE) clinicians that make up the 39 districts in Queensland. Each district is levied according to the percentage of clinicians that work in each district.

The selection of resources was based on feedback from a survey that was conducted by the Queensland health department. All stakeholders were eligible to participate in this survey, including librarians, who also assisted in the distribution of the survey forms. Future product selection will be determined by a board with representatives from all relevant interest groups, e.g., allied health, physicians, nurses, and librarians.

Because of the sheer geographic size of the state of Queensland, funds have also been provided more recently for reimbursement of travel expenses incurred by rural health librarians. These librarians travel around the state providing training in the use of CKN resources to those in remote areas.

Resources which are available to all Queensland public health employees include Clinical Evidence, MD Consult, Emedicine, MEDLINE, MIMS, Micromedex, CINAHL, PsycINFO, Harrison's, and other resources [29].

\section{Health Information Access Project}

The fifth and final programme discussed in this paper is the Health Information Access Project (HIAP) ${ }^{4}$ It was established in the Australian Capital Territory (ACT) in July 2003. ACT has a population of over 350000 [30]. The idea for the project came from a librarian - the Director of Library Services at Canberra Hospital (ACT Health) - who was also the project manager of HIAP. Funding was provided for 1 year and was obtained from the ACT Health Department. The programme was based on CIAP.

Resources were selected by a committee consisting of five individuals, with the project manager acting as chair. The other members of the committee each represented nurses, allied health professionals, consumer organisations, and general medical practitioners.

The aim of the programme was to provide access to health practitioners who were unable to ordinarily access clinical information from their place of work. Access to these resources is available to general medical practitioners, allied health staff, public health library staff, community health professionals, and consumer health organisations. To date, over 500 individual registrations have been created for use by health professionals in the territory, although only approximately 400 registered users chose to use the service. The programme is not restricted to public health professionals; it is open to health professionals unable to otherwise access clinical information resources.

The electronic resource subscriptions include MIMS, Micromedex, Australian Medicines Handbook, Therapeutic

\footnotetext{
${ }^{2}$ Information is based on data obtained during interviews held in May 2004, with Maureen Bradford, Project Manager, and Cheryl Hamill, Librarian, unless otherwise stated.

${ }^{3}$ Unless otherwise indicated, information is based on data obtained during an interview in May 2004, with Lyn Perks, Project Manager. ${ }^{4}$ Unless otherwise stated, information is based on data obtained during an interview in May and July 2004, with Saroj Bhatia, Project Manager.
} 
Guidelines, Harrison's, and others. The unified search environment can be used to search across resources simultaneously, a resource also used by CIAP.

This programme ceased to operate on 20 July 2004. However, funds have been secured for continued assistance to health professionals in need of clinical information. The new programme will not operate under the name of HIAP. It will be managed by the ACT Health Library by the project manager of HIAP, the Director of Library Services. Details of how the programme will proceed are not yet available. However, users of HIAP will not be disadvantaged and will be able to re-register to ensure continued access to resources while details of the new programme are being finalized.

\section{Discussion}

One thing that is apparent from reading some of the programme reports (which are readily available via a programme's Web site) is that very little is mentioned regarding the impact of the value-added services libraries provide on the promotional and training activities provided in relation to the various programmes. Librarian input is mentioned in some of the reports on CIAP, for example, such as the report by Gosling and Westbrook [31]. Wensley [32] acknowledges that "librarians embracing the CIAP are integral to the continuing success of the Web site, providing valuable education and training to clinicians using the Internet".

Without libraries attempting to incorporate access to these resources into their intranets (where possible) to make it seamless and easier for their patrons to access and the promotion of these resources as part of user education programmes, it is likely that the programmes would have been less successful. It appears as though only papers written by librarians such as Gillian Wood [33] on CIAP and Janet Iffinger [34] on CKN, for example, focus on the library issues associated with these programmes.

Perhaps this indicates more than a simple omission on the part of the researchers and possibly justifies the call by some librarians for more input into the selection of resources and more general input into these programmes. This has more recently been illustrated in the Victorian programme $\mathrm{CHC}$, when the President of Health Libraries Inc., David Lloyd, in the tender document advertised in The Age on 28 June 2004 [35], gave voice to concerns about the lack of librarian involvement in the selection of resources for CHC. Lloyd also expressed the hope that librarians will be given the opportunity to be more involved with the new CHC [36]. Queensland librarians have also expressed the desire to be more involved with CKN (L. Perks, personal communication, 2004). Gosling and Westbrook report that based on the interviews of librarians in their study, while the value of CIAP was acknowledged, the librarians were also concerned about the "content, training, searching skills, and consultation process" [37].

\section{Equity of access}

It is apparent that the programmes and consortium (based on either the literature and (or) information available on the programmes' Web sites) all aim to provide better patient outcomes by making clinical information resources available via an electronic health library. They also attempt to achieve more equitable access to these resources. But can these initiatives truly provide equitable access?

To consider the notion of equitable access, one must start with a definition. The New Shorter Oxford English Dictionary defines equity as "fairness, impartiality, evenhanded dealing... that which is fair and right" [38]. To ensure equity of access to clinical information, therefore, one must expect or demand that access to such information is provided without bias or partiality. In addressing the question of equity of access, certain issues emerge for consideration and discussion:

(1) The consortium and most of the programmes mentioned address the needs of clinical professionals in the public health sector only (with the exception of HIAP) and exclude all private health services. However, privately funded hospitals comprise $42 \%$ of the hospitals in Australia (537 compared with 1283) [39], based on data available in the most recent edition of the Australian Hospitals Directory. The main reason for the exclusion of private facilities is clear: the idea for attempting to establish clinical knowledge programmes and the consortium came from within state health department settings and naturally their financial concerns would be for state health department funded hospitals and health services only. The health departments, however, do continue to prescribe regulatory conditions for the private health sector.

(2) Notwithstanding the availability in principle of these programmes, certain public hospital user groups are excluded from complete access to resources offered by some of these programmes. Such user groups are only able to access these resources at the hospital; therefore, these groups are unable to access the resources $24 \mathrm{~h}$ per day, 7 days per week. User groups affected by this include affiliated medical students of public teaching hospitals and general medical practitioners who hold honorary staff status at public hospitals. These restrictions affect teaching hospitals of Southern Health in Victoria and others across the country.

In light of these two points, one cannot state that complete equity of access has been achieved through the establishment of these initiatives. And even if we were to limit the context and qualify the statement by stating that equity of access has been achieved within the limited setting of state-funded public health institutions, one must then consider the following. Providing electronic information resources using the Internet as the delivery mechanism means that access is very much dependent on the availability of Internet access. Equity of access can only be achieved if all eligible clinicians have access to a personal computer that has access to the Internet. If public health institutions are unable to provide access to the Internet to their clinicians, one would have to question the relevance of spending millions of dollars on such programmes. What would be the point of providing these resources if 50\% of a state's clinicians, for example, worked in organisations that constantly had serious network difficulties, resulting in unacceptable response times when attempting to access any of these resources or if clinicians simply did not have access to a personal computer?

An additional point of interest is that some clinicians in some area health networks may not be granted permission to 
use the Internet at the workplace. Some area health networks require a supervisor's permission before user identification and passwords can be set up for employees to access the Internet. Simply being an employee at such an organisation does not entitle the employee to automatic unrestricted Internet access. This is the case with Southern Health in Victoria. Depending on one's supervisor, some clinicians may or may not be able to access the Internet, depending on whether the supervisor deems it necessary for that person to access the clinical resources electronically via the $\mathrm{CHC}$, for example, to perform their clinical duties. Supervisors failing to provide permission for staff members to have access to the Internet may do so out of concern arising from budgetary considerations (if each department is charged according to the amount of Internet usage by its staff) or from ignorance (i.e., not being aware of these resources or not believing in the value of such information tools in clinical practice).

In an ideal world, issues such as network reliability, speed of Internet access, and availability of personal computers would not be mentioned as hindrances in the uptake of initiatives such as these. But in reality, these issues vary from organisation to organisation. The programmes outlined in this paper have been established first and foremost to address the availability of clinical information resources and not the technological or hardware issues of public health organisations in each of the states, despite the initial attempts of using CIAP funds to deliver some hardware during its initial phases. Essentially, hardware and technological issues become an organisational issue.

As things are not considered as being equal in this sense, in terms of Internet availability or network reliability, one cannot state that equity of access has been achieved, even when applied to the limited context of the public health setting. But if information technology issues were not a consideration in addressing the question of equitable access, then one can state that access to these resources have been provided in an equitable manner to those employed in the public health sector. According to Marriott, Darmoni et al. state that "there is evidence contained in library and information research literature that easy access to knowledge resources promotes their uptake" [40].

These initiatives may not provide complete equity of access, but one should not ignore, however, the implications of the actions taken by clinicians in Western Australia and in Victoria. The Western Australians fought to reinstate CIAO, while Victorian librarians, alarmed at the prospect of not having access to CHC resources after August 2004, initiated lobbying efforts by Victorian clinicians for the continuation of CHC. It is evident from these events alone that these programmes are of tremendous value to clinicians in these two states. Indeed, they are also of tremendous value to librarians who, owing to budget restrictions, may never have been able to provide electronic resources for their clinicians on such a scale otherwise.

\section{Future directions}

Based on data obtained from interviews with current project managers of CIAP, CKN, HIAP, and CIAO (P. Romain, L. Perk, S. Bhatia, and M. Bradford, respectively) and a conversation with a past project manager of CHC (C. Purdon, personal communication, 2003), financial figures for the provision of the resources provided by these programmes was obtained. The total figure for the four states and one territory amounted to almost \$10 million for the 2003-2004 financial year. Financial figures were not provided for the SA consortium. The financial buying power of the states and territory would be even greater if their buying power were combined, instead of each state and territory acting as separate entities within their current geographical constraints. A more equitable solution would be to dissolve all the current programmes and the consortium, replace them with a national programme, and include the only state and territory currently without a clinical knowledge programme (Tasmania and the Northern Territory). Such a programme would have to extend membership to all health institutions, private or public. This would provide the means for all clinicians in all states and territories to have access to the same resources as colleagues in a similar health facility in another state.

Evidence regarding the benefits of establishing a national programme is demonstrated by the National electronic Library for Health $(\mathrm{NeLH})$ pilot for the National Health Service (NHS) in the United Kingdom (UK), a programme similar to CIAP but on a national scale. Cost for the provision of access to one electronic resource, Clinical Evidence, is cited as costing far more to supply to 500 NHS libraries and 600000 staff in the UK (at a cost of $£ 6$ million), than it is to supply it nationally to all NHS staff (at a third of the cost) [41]. NHS reported that a $40 \%$ savings can be enjoyed by providing electronic resources for all NHS agencies on a national scale [42]. Alternatively, the example provided by the South Australian consortium, which has been used as the model for the Victorian Health Libraries Consortium (but with flexibility in the membership eligibility), could possibly become the basis of a model for a national consortium of health libraries, similar to that proposed by the Canadian Health Libraries Association. This could provide greater opportunities for all health libraries, large or small, with membership extended to include private as well as public health facility libraries. Unlike the United States of America, Australia does not have an Australian national library of medicine.

Commonwealth and state and territory government cooperation has witnessed the establishment of national initiatives such the National Mental Health Plan and research and development projects such as HealthConnect [43]. HealthConnect is a project that will attempt to implement an integrated medical records system across the country that will assist clinicians by facilitating the accessing of a patient's medical records at point of care. It is clear that the governments see the value of an integrated system for medical records, so why not extend that to include a national uniform set of minimum standards for electronic clinical information? Legislation could be passed to ensure its adoption throughout all Australian health facilities, whether public or private, and to ensure it is applicable to all states and territories. Surely, this would ensure a more equitable distribution of vital information for clinicians. It would also ensure that the clinicians providing patient care all have access to the basic necessary core information resources (e.g. drug databases, evidence-based medicine resources, clinical guidelines, etc.). 
Establishing such a national uniform set of minimum standards for clinical information, if legislated and enforced, could only succeed if a standard for provision of access to computers was maintained across all health facilities. Such a standard, if legislated, could ensure, for example, that each ward in a hospital must have a minimum of $\mathrm{X}$ number of computers, depending on the number of staff stationed on the ward, or a formula ensuring one computer per $\mathrm{X}$ number of FTE staff in clinical or clinical support areas could be adopted. In practice, this could only succeed in organisations with the appropriate infrastructure in place to support the additional hardware and software.

\section{Conclusion}

While it cannot be said that equity of access has been achieved, the provision of clinical information resources via the Web sites of CIAP, CKN, CIAO, HIAP, CHC, and SALUS provide a good framework for attempting to achieve equity in access. To achieve true equity, issues such as inclusion criteria for such initiatives, availability of hardware, and other organisational issues would have to be addressed.

\section{References}

1. Australian Institute of Health and Welfare. Australia's Health 2004: the ninth biennial health report of the Australian Institute of Health and Welfare. Canberra (Australia): Australian Institute of Health and Welfare; 2004. p. 245.

2. ATA Professional Services. The Australian Hospitals Directory 2004. Doonan (Australia): ATA Professional Services.

3. Australian Institute of Health and Welfare, op. cit. p. 243.

4. Jacoby B, Rooke A. University funding for Australian teaching hospital libraries. In: Proceedings of the 9th Specials, Health and Law Librarians Conference; 2001 August 26-29; Melbourne, Australia [accessed July 2004]. Available from: http:// conferences.alia.org.au/shllc2001/papers/jacoby.rooke.html.

5. ATA Professional Services, op. cit.

6. Williamson K. Research techniques: questionnaires and interviews. In: Williamson K, editor. Research methods for students, academics and professionals: information management systems. 2nd ed. Wagga Wagga, NSW (Australia): Centre for Information Studies, Charles Sturt University; 2002. p. 243.

7. Ibid. p. 243.

8. Ibid. p. 244.

9. Wyatt J. The Clinical Information Access Project, New South Wales: lessons from an NeLH precursor. Available from: http://www.ucl.ac.uk/kmc/kmc2/News/ACKM/ackm3/ wyatt.html [accessed May 2004].

10. Ayres D, Wensley M. The Clinical Information Access Project. Med J Aust. 1999;171:544-546.

11. Australian Bureau of Statistics. Year Book Australia. Population: population size and growth. Canberra (Australia): AusStats; 2004 [accessed July 2004];1301. Available from: http://www.abs.gov.au.

12. Clinical Information Access Programme [homepage on the Internet]. New South Wales: New South Wales Government [accessed July 2004]. Available: http://www.clininfo.health. nsw.gov.au/.

13. Petersen M, Harris L. SALUS: online co-operation between South Australian health libraries. Health Inf Libr J. 2002;19:83.

14. Australian Bureau of Statistics, op. cit.
15. Harris L, Petersen M. Sharing the burden: a model for consortium purchasing for health libraries. J Med Libr Assoc. 2003;91(3):361.

16. Ibid.

17. Ibid.

18. Clinicians Health Channel: Results of Phase 1 Survey. Victoria (Australia): State Government Department of Human Services, Victoria; 2000 July [accessed December 2003]. Available from: http://www.clinicians.vic.gov.au/about.html.

19. Australian Bureau of Statistics, op. cit.

20. Lloyd D. President's Report. Health Inform. 2004;13(2). In press.

21. Ibid.

22. Health Staff Australia [homepage on the Internet]. Liberals back the Clinicians Health Channel. Heidelberg (Australia): Health Staff Australia; 2004 April [accessed July 2004]. Available from: http://www.healthstaff.com.au/News2.asp?NewsID=94880.

23. Clinicians Health Channel [homepage on the Internet] Victoria (Australia): State Government Department of Human Services, Victoria [accessed July 2004]. Available from: http:// www.health.vic.gov.au/clinicians.

24. Ibid.

25. Australian Bureau of Statistics, op. cit.

26. Clinical Information Access Online [homepage on Internet]. Available from: http://www.ciao.health.wa.gov.au/about.cfm [accessed May 2004].

27. Queensland Health. Clinicians Knowledge Network: An awareness survey. July 2002 [accessed December 2003]. Available at: http://ckn.health.qld.gov.au/content/docs/CKN_survey_report.pdf.

28. Australian Bureau of Statistics, op. cit.

29. Clinicians Knowledge Network [homepage on Internet]. Available from: http://ckn.health.qld.gov.au [accessed May 2004].

30. Australian Bureau of Statistics, op. cit.

31. Gosling S, Westbrook J. The influence of preofessional and organisational factors on health professional use of online evidence. An evaluation of the Clinical Information Access Program (CIAP). 2002. Sydney, New South Wales (Australia): Centre for Health Informatics, University of New South Wales.

32. Wensley MM. The clinical information access program (CIAP): netting a nation of clinicians. New South Wales (Australia): Clinical Systems Unit, Information Management and Clinical Systems [accessed January 2004]; p. 6. Available from: http://www.ciap.health.nsw.gov.au/resources/conferences/ apami/paper/61-paper.pdf.

33. Wood G. Clinical Information Access Project - revolution for information professionals. Strait to the future: 8th Asia Pacific Specials, Health and Law Librarians Conference. Hobart: Australian Library and Information Association; 1999 [accesed December 2003]. Available from: http://conferences.alia.org.au/ shllc1999/papers/wood.html.

34. Iffinger J. Travel, training and warmware - critical success factors for utilizing CKN in the central zone. Proceedings of the 10th Asia Pacific Special, Health and Law Librarians Conference. 2004 August 24-27; Adelaide, Australia. Available from: http://conferences.alia.org.au/shllc2003/papers/iffinger.html [accessed May 2004].

35. Lloyd D. President's Report. Health Inform. 2004;13(2). In press.

36. Ibid.

37. Gosling S, Westbrook J., op. cit. p. 37.

38. Trumble WR, Brown L, Stevenson A, Siefring J, editors. The New Shorter Oxford English Dictionary. Vol. 1. Oxford: Oxford University Press; 2003:843.

39. ATA Professional Services, op. cit. 
40. Marriott R. Yes, but how do we know if it's working? Evidence regarding impact on clinical practice of access for health service staff to bibliographic databases and full text electronic journals. Libr Rev (Lond). 51(7):362.

41. NHS Information Authority. National electronic Library for Health: Outline Business Case. Birmingham (UK): NHS Information Authority [accessed December 2003]. Available from: http://www.nhsia.nhs.uk/nelh/background.asp.
42. Australian Institute of Health and Welfare, op. cit., p. 350.

43. NHS Information Authority. National electronic Library for Health: Outline Business Case [Summary]. Birmingham (UK): NHS Information Authority [accessed July 2004]. Available from: http://www.nhsia.nhs.uk/pdocs/board/corp_011101_2.pdf. 